\title{
Correlation of miR-425-5p and IL-23 with pancreatic cancer
}

\author{
YANMIN LU ${ }^{1}$, XINQING WU² and JINXIANG WANG ${ }^{3}$ \\ ${ }^{1}$ Department of Radiotherapy, Traditional Chinese Medical Hospital of Huangdao District, Qingdao, Shandong 266555; \\ ${ }^{2}$ Department of Clinical Laboratory, Shouguang Hospital of Traditional Chinese Medicine, Shouguang, Shandong 262700; \\ ${ }^{3}$ Department of Radiotherapy, Weifang Medical University Hospital, Weifang, Shandong 261031, P.R. China
}

Received October 8, 2018; Accepted February 12, 2019

DOI: $10.3892 /$ ol.2019.10099

\begin{abstract}
The aim of this study was to detect the levels of miR-425-5p and IL-23 in tissues of pancreatic cancer patients and to explore their effects on pancreatic cancer. A retrospective analysis of 76 cases of pancreatic cancer tissue specimens and normal fresh tissue specimens at $50 \mathrm{~mm}$ adjacent to the corresponding cancer surgically resected in the first diagnosis was performed, in the Department of Radiotherapy of Traditional Chinese Medical Hospital of Huangdao District and Weifang Medical University Hospital from October 2015 to October 2016. RT-qPCR was used to detect miR-425-5p levels in pancreatic cancer and adjacent tissues, and ELISA to detect IL-23 levels in the tissues. The correlation of miR-425-5p and IL-23 in pancreatic cancer tissues with clinicopathological parameters was analyzed. The expression levels of miR-425-5p and IL-23 were significantly higher in pancreatic cancer tissues than those in adjacent tissues, with statistically significant difference $(\mathrm{P}<0.001)$. The expression level of miR-425-5p was positively correlated with IL-23 in pancreatic cancer tissues $(\mathrm{r}=0.432, \mathrm{P}<0.001)$, and of miR-425-5p in tumor tissues of pancreatic cancer patients was correlated with lymph node metastasis, clinical stage and differentiation degree $(\mathrm{P}<0.001)$. That of IL-23 in tumor tissues of pancreatic cancer patients was correlated with clinical stage $(\mathrm{P}<0.001)$. The expression levels of miR-425-5p and IL-23 in tissues of pancreatic cancer patients are higher than those in adjacent tissues. The expression level of miR-425-5p is positively correlated with that of IL-23 in pancreatic cancer tissues, and that of miR-425-5p in tumor tissues of pancreatic cancer patients was correlated with lymph node metastasis, clinical stage and differentiation degree. IL-23 in tumor tissues of pancreatic cancer patients was correlated with clinical stage. miR-425-5p and IL-23 may be involved in the pathological development of pancreatic cancer.
\end{abstract}

Correspondence to: Dr Jinxiang Wang, Department of Radiotherapy, Weifang Medical University Hospital, 2428 Yuhe Road, Kuiwen, Weifang, Shandong 261031, P.R. China

E-mail:wwc3gh@163.com; xiangmeihai99@163.com

Key words: miR-425-5p, IL-23, pancreatic cancer, correlation

\section{Introduction}

Pancreatic cancer is a fast-growing and highly aggressive malignant digestive system tumor (1), usually occurring in males. The peak age of its onset is 40-70 years, with the age of onset getting younger (2). The prognosis of pancreatic cancer is extremely poor, and the average survival time is generally less than half a year, with a 5-year survival rate of only $5 \%$ (3). Tumor resection is still the only way to hopefully cure it. However, since most patients have been diagnosed with lymph node metastasis and distant metastasis, failing to meet surgical conditions, the surgical resection rate is very low, only $5-30 \%(4,5)$. According to reports in the literature, pancreatic cancer is correlated with congenital and acquired factors such as genetic factors, smoking, obesity, drinking, diabetes mellitus and chronic pancreatitis. Those having risk factors described above, you should take regular physical examinations to prevent pancreatic cancer (6).

It has been reported in the literature that miRNAs are involved in cell proliferation, apoptosis, differentiation and embryonic development (7). In recent years, the relationship between miRNAs and tumors have become a research hotspot (8). The miR-425 family, containing miR-425-3p and miR-425-5p (9), is abnormally expressed in tissues such as the gastrointestinal tract, immune system, and heart, liver and lung, closely related to the development of various diseases and participating in their biological processes (10). Related studies have found that miR-425-5p can promote the proliferation, invasion and migration of pancreatic cancer cells (11). Having 35\% homology with IL-12, IL-23 is a novel cytokine that plays an important role in autoimmune diseases, infections and tumors (12). In the study of Langowski et al (13), IL-23 was found to play a role in promoting tumor growth in mice deficient in IL-23p19 (one of two subunits of IL-23).

miR-425-5p and IL-23 have rarely been studied in clinical aspects of pancreatic cancer. Therefore, the aim of this study was to investigate their expression levels and clinical significance in pancreatic cancer, which plays a certain indicative role in the diagnosis and treatment and in the prediction of prognosis.

\section{Materials and methods}

General information. A retrospective analysis of 76 cases of pancreatic cancer tissue specimens and normal fresh tissue 
Table I. miR-425-5p primer and internal reference sequence.

\begin{tabular}{lll}
\hline Gene & \multicolumn{1}{c}{ Upstream primer } & \multicolumn{1}{c}{ Downstream primer } \\
\hline miR-425-5p & 5'-GGGGAGTTAGGATTAGGTC-3' & 5'-TGCGTGTCGTGGAGTC-3' \\
U6 & 5'-CTCGCTTCGGCAGCACA-3' & 5'-AACGCTTCACGAATTTGCGT-3'
\end{tabular}

Table II. Comparison of miR-425-5p and IL-23 levels between pancreatic cancer tissues and adjacent tissues.

\begin{tabular}{lccc}
\hline Group & $\mathrm{n}$ & $\mathrm{miR}-425-5 \mathrm{p}$ & $\mathrm{IL}-23(\mathrm{pg} / \mathrm{ml})$ \\
\hline Pancreatic cancer tissues & 76 & $0.85 \pm 0.23$ & $286.69 \pm 18.32$ \\
Adjacent tissues & 76 & $0.31 \pm 0.09$ & $234.36 \pm 12.68$ \\
t value & & 19.06 & 20.48 \\
P-value & & $<0.001$ & $<0.001$ \\
\hline
\end{tabular}

specimens at $50 \mathrm{~mm}$ adjacent to the corresponding cancer surgically resected in the first diagnosis from October 2015 to October 2016 in Traditional Chinese Medical Hospital of Huangdao District (Qingdao, China) and Weifang Medical University Hospital (Weifang, China) was performed. The specimens were preserved in liquid nitrogen immediately after excision and then transferred to a refrigerator at $-80^{\circ} \mathrm{C}$. Adjacent tissues were confirmed as no obvious infiltration of cancer cells or inflammatory cells. The average age of patients was $48.08 \pm 16.52$ years, with 39 males and 37 females. All subjects were diagnosed as pancreatic cancer by pancreatic biopsy or pathology, without chemotherapy or radiotherapy before operation. They were excluded during pregnancy and lactation. Those with primary and malignant tumor diseases in other parts and tissues, with heart, liver and kidney dysfunction or with pancreas-related operation within six months prior to admission were excluded.

This study was approved by the Ethics Committee of Traditional Chinese Medical Hospital of Huangdao District and Weifang Medical University Hospital. All subjects and their family members signed the informed consent form with complete clinical information.

Detection of miR-425-5p. TRIzol lysate (1 ml) (Shanghai Pufei Biotechnology Co., Ltd., Shanghai, China) was added after $100 \mathrm{mg}$ of tissue ground and pulverized, to extract total RNA from the tissue. After that, $1.5 \%$ agarose gel electrophoresis was used to analyze RNA integrity, and the micronucleic acid analyzer (Beijing Meilinhengtong Instrument Co.,Ltd., Beijing, China) to detect the extracted RNA purity and concentration. The A260/A280 value was considered to meet experimental requirements between 1.9 and 2.0. After RNA extraction, RT-qPCR reaction was performed using a Countess II FL Automated Cell Counter Real-Time PCR instrument (Applied Biosystems; Thermo Fisher Scientific, Inc., Waltham, MA, USA). The reverse transcription reaction system was: $1.0 \mu 1$ of oligo(dT) primer, $1.0 \mu \mathrm{l}$ of dNTP mixture, $1.0 \mu \mathrm{l}$ of $2.5 \mathrm{U} / \mu \mathrm{l}$ polymerase, $2 \mu \mathrm{g}$ of total RNA, and ribonuclease distilled water added to $10 \mu \mathrm{l}$; water bath at $42^{\circ} \mathrm{C}$ for $90 \mathrm{~min}$, reaction at $95^{\circ} \mathrm{C}$ for $5 \mathrm{~min}$, and then immediately ice bath for $5 \mathrm{~min}$. After the reverse transcription reaction, PCR amplification was performed. The PCR amplification system was: $2 \mu 1$ of cDNA template, $25 \mu 1$ of SYBR-Green Mix, $0.5 \mu l$ of each of upstream primer and downstream primer, and double distilled water added to $50 \mu \mathrm{l}$, pre-denaturation at $95^{\circ} \mathrm{C}$ for $3 \mathrm{~min}$, denaturation at $95^{\circ} \mathrm{C}$ for $30 \mathrm{sec}$, annealing at $55^{\circ} \mathrm{C}$ for $30 \mathrm{sec}$, extension at $72^{\circ} \mathrm{C}$ for $60 \mathrm{sec}$, for a total of 30 cycles, and after completion of the cycle, extension at $72^{\circ} \mathrm{C}$ for $5 \mathrm{~min}$. U6 was used as an reaction internal reference. All samples were repeated for 3 wells. The $2^{-\mathrm{ACq}}$ method (14) was used to detect the expression level of miR-425-5p. The primer sequence was designed and synthesized by Hepeng (Shanghai) Biotechnology Co., Ltd., Shanghai, China, as shown in Table I.

Detection of IL-23. In total 76 cases of cancer tissues and adjacent normal tissues surgically resected from pancreatic cancer patients were taken and weighed after the fat and blood clots were removed. After washed 3 times with D-Hank's cleaning solution containing double-antibody (Shanghai Chunshi Biotechnology Co., Ltd., Shanghai, China), the tissue was cut into small pieces and placed in an ELISA plate. RPMI-1640 complete medium containing double-antibody (Shanghai Bosheng Biotechnology Co., Ltd., Shanghai, China) was added to the plate, and incubated at $37^{\circ} \mathrm{C}$ for $24 \mathrm{~h}$. Then, the medium was collected, centrifuged in a centrifuge tube at $12,600 \mathrm{x} \mathrm{g}$ for $5 \mathrm{~min}$ at $4^{\circ} \mathrm{C}$, with the supernatant taken. ELISA was used to detect IL-23 levels in cancer tissues and adjacent tissues. The kit and the sample to be tested were taken from the refrigerator $30 \mathrm{~min}$ in advance to balance the room temperature, with a sample well, a standard well and a blank well set. The Antus PHOmo automatic microplate reader (Jinan Yuteng Biotechnology Co., Ltd., Jinan, China) was used to measure the OD value of each well at the wavelength of $450 \mathrm{~nm}$, to calculate IL-23 concentration.

Statistical analysis. SPSS 20.0 (Shanghai Kabei Information Technology Co., Ltd., Shanghai, China) statistical software was used for analysis, Student's t-test for measurement data which was expressed as means $\pm \mathrm{SD}$, and Pearson for correlation analysis. $\mathrm{P}<0.05$ was considered to indicate a statistically significant difference.

\section{Results}

Comparison of miR-425-5p and IL-23 levels between pancreatic cancer tissues and adjacent tissues. The expression levels of miR-425-5p and IL-23 were significantly higher in pancreatic cancer tissues than those in adjacent tissues, with statistically significant differences $(\mathrm{P}<0.001)$ (Figs. 1 and 2; and Table II. 


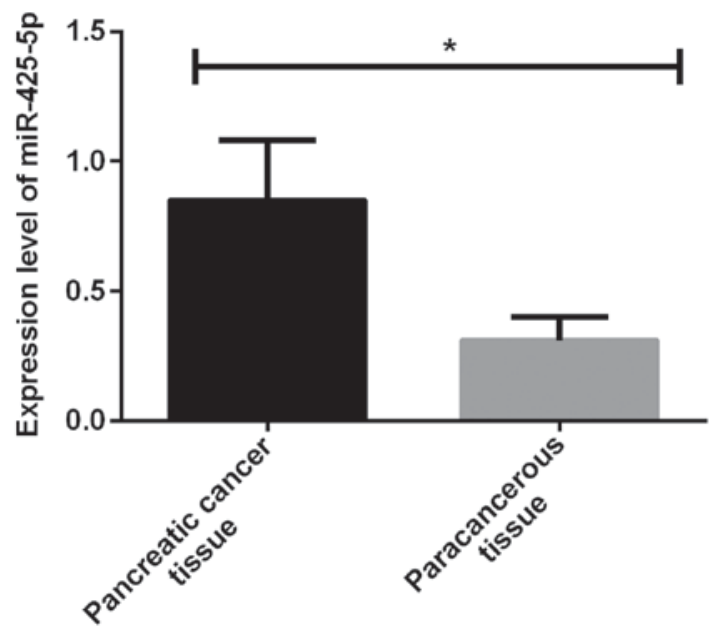

Figure 1. Comparison of miR-425-5p level between pancreatic cancer tissues and adjacent tissues. The results of RT-qPCR showed that the expression level of miR-425-5p was significantly higher in pancreatic cancer tissues than that in adjacent tissues, with statistically significant differences $\left({ }^{*} \mathrm{P}<0.001\right)$

Correlation analysis of miR-425-5p with $I L-23$ in pancreatic cancer. The expression level of miR-425-5p was positively correlated with that of IL-23 in pancreatic cancer tissues $(\mathrm{r}=0.432, \mathrm{P}<0.001)$ (Fig. 3).

Correlation of miR-425-5p and IL-23 with clinical pathology of pancreatic cancer. The expression level of miR-425-5p in tumor tissues of pancreatic cancer patients was not significantly correlated with age, sex, tumor size and distant metastasis ( $P>0.05)$, but correlated with lymph node metastasis, clinical stage and differentiation degree $(\mathrm{P}<0.001)$. Expression of IL-23 in tumor tissues of pancreatic cancer patients was not significantly correlated with age, sex, tumor size, lymph node metastasis, distant metastasis or differentiation degree $(\mathrm{P}>0.05)$, but correlated with clinical stage $(\mathrm{P}<0.001)$ (Table III).

\section{Discussion}

According to statistics, the mortality of pancreatic cancer ranks fourth among cancer patients in the United States and sixth in China. With the title of 'king of cancer', it has clinical features of short course of disease, rapid progress and low survival rate (15). Studies have shown that the miR-425-5p family, correlated with the post-transcriptional regulation of a variety of genes, is abnormally expressed in various cancer tissue samples such as liver cancer, laryngeal cancer and gastric cancer (16). According to reports in the literature, as an important inflammatory factor in the tumor microenvironment, IL-23 usually promotes tumor angiogenesis and inhibits $\mathrm{CD}^{+}$cell infiltration, which is of great significance in the development of tumors (17). In order to improve the early screening rate and treatment level of pancreatic cancer, in this study, the correlation of miR-425-5p and IL-23 with the clinical pathology of pancreatic cancer was studied, providing ideas for improving the prognosis and survival of pancreatic cancer patients.

The present study showed that the expression levels of miR-425-5p and IL-23 were significantly higher in pancreatic cancer tissues than those in adjacent tissues, with

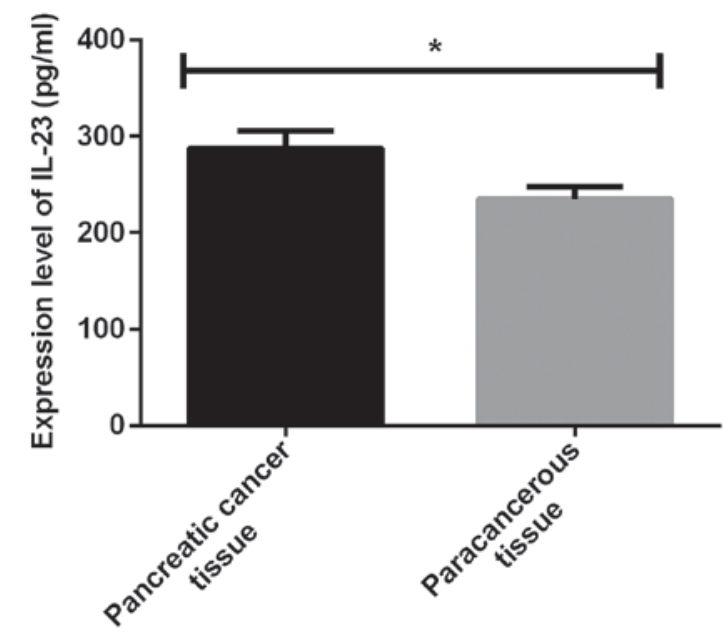

Figure 2. Comparison of IL-23 level between pancreatic cancer tissues and adjacent tissues. The results of ELISA showed that the expression level of IL-23 was significantly higher in pancreatic cancer tissues than that in adjacent tissues, with statistically significant differences $\left({ }^{*} \mathrm{P}<0.001\right)$.

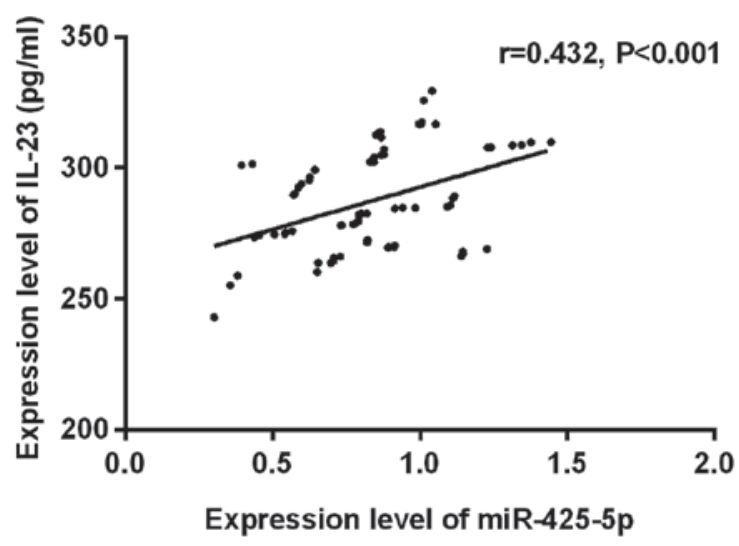

Figure 3. Correlation analysis of miR-425-5p with IL-23 in pancreatic cancer. The results of Pearson showed that the expression level of miR-425-5p was positively correlated with that of IL-23 in pancreatic cancer tissues ( $r=0.432$, $\mathrm{P}<0.001)$

statistically significant differences $(\mathrm{P}<0.001)$. In the study of Zhang et al (16), it was found that miR-425-5p, significantly higher in gastric cancer tissues than in adjacent tissues, promoting invasion and metastasis of gastric cancer cells. Shime et al (18)showed that IL-23 is a pro-inflammatory factor. Furthermore, it is highly expressed in mouse breast cancer tissues (19). IL-23 that is highly expressed in breast cancer tissues may be involved in the occurrence of breast cancer (20). The above conclusions are consistent with our findings. The expression level of miR-425-5p was positively correlated with that of IL-23 in pancreatic cancer tissues $(r=0.432, \mathrm{P}<0.001)$. No correlation study of the expression level of miR-425-5p with that of IL-23 in tumors has been reported. However, inflammatory factors and immune function are usually abnormal in tumor patients, so IL-23 may affect miR-425-5p expression by regulating $\mathrm{T}$ cells in tumor tissues. The expression level of miR-425-5p in tumor tissues of pancreatic cancer patients was not significantly correlated with age, sex, tumor size and distant metastasis ( $\mathrm{P}>0.05)$, but correlated with lymph node metastasis, clinical stage and 
Table III. Correlation of miR-425-5p and IL-23 with clinical pathology of pancreatic cancer.

\begin{tabular}{|c|c|c|c|c|c|c|c|}
\hline Characteristics & $\mathrm{n}$ & $\operatorname{miR}-425-5 p$ & $\mathrm{t}$ value & P-value & IL-23 (pg/ml) & $\mathrm{t}$ value & P-value \\
\hline Age (years) & & & 1.803 & 0.076 & & 1.188 & 0.239 \\
\hline$\geq 48$ & 41 & $0.92 \pm 0.25$ & & & $289.53 \pm 23.64$ & & \\
\hline$<48$ & 35 & $0.82 \pm 0.23$ & & & $296.45 \pm 27.16$ & & \\
\hline Sex & & & 1.606 & 0.113 & & 0.896 & 0.373 \\
\hline Male & 39 & $0.89 \pm 0.24$ & & & $283.52 \pm 24.16$ & & \\
\hline Female & 37 & $0.81 \pm 0.19$ & & & $289.05 \pm 29.53$ & & \\
\hline Tumor size & & & 1.570 & 0.121 & & 1.104 & 0.273 \\
\hline$\geq 5 \mathrm{~cm}$ & 34 & $0.96 \pm 0.28$ & & & $292.58 \pm 26.88$ & & \\
\hline$<5 \mathrm{~cm}$ & 42 & $0.87 \pm 0.22$ & & & $285.47 \pm 28.73$ & & \\
\hline Lymph node metastasis & & & 4.257 & $<0.001$ & & 1.542 & 0.127 \\
\hline Yes & 37 & $0.98 \pm 0.31$ & & & $286.28 \pm 24.83$ & & \\
\hline No & 39 & $0.75 \pm 0.13$ & & & $277.35 \pm 25.62$ & & \\
\hline Distant metastasis & & & 1.407 & 0.164 & & 1.156 & 0.251 \\
\hline Yes & 24 & $0.91 \pm 0.27$ & & & $293.57 \pm 26.38$ & & \\
\hline No & 52 & $0.83 \pm 0.21$ & & & $286.34 \pm 24.85$ & & \\
\hline Clinical stage & & & 4.774 & $<0.001$ & & 8.315 & $<0.001$ \\
\hline $\mathrm{I}+\mathrm{II}$ & 36 & $0.72 \pm 0.15$ & & & $267.82 \pm 20.36$ & & \\
\hline III+IV & 40 & $0.97 \pm 0.28$ & & & $315.76 \pm 28.69$ & & \\
\hline Differentiation degree & & & 2.096 & 0.040 & & 0.564 & 0.575 \\
\hline Low and medium & 42 & $0.92 \pm 0.29$ & & & $286.15 \pm 21.05$ & & \\
\hline High & 34 & $0.79 \pm 0.24$ & & & $283.43 \pm 20.73$ & & \\
\hline
\end{tabular}

differentiation degree $(\mathrm{P}<0.001)$. The results of Sun et al $(21)$ are basically consistent with ours. They found that the high expression of miR-425-5p in cervical cancer tissues is correlated with tumor stage and lymph node metastasis. The expression level of IL-23 in tumor tissues of pancreatic cancer patients was not significantly correlated with age, sex, tumor size, lymph node metastasis, distant metastasis and differentiation degree $(\mathrm{P}>0.05)$, but correlated with clinical stage $(\mathrm{P}<0.001)$. Petanidis et al $(22)$ found that IL-23 is correlated with the TNM staging of colon cancer, but not significantly correlated with age, sex, tumor size, lymph node metastasis and differentiation degree. This is basically consistent with our results. It is possible that lactic acid produced by tumor cells can cause mononuclear macrophages in tumors to produce IL-23 and activate cAMP/PKA signaling pathway, thereby promoting tumor growth (23).

In summary, both miR-425-5p and IL-23 are highly expressed in pancreatic cancer tissues. The expression level of miR-425-5p is positively correlated with that of IL-23 $(r=0.432, P<0.001)$. Expression of miR-425-5p in tumor tissues of pancreatic cancer patients is correlated with lymph node metastasis, clinical stage and differentiation degree, and that of IL-23 in tumor tissues of pancreatic cancer patients is correlated with clinical stage. It is suggested that miR-425-5p and IL-23 may be involved in the pathological development of pancreatic cancer.

\section{Acknowledgements}

Not applicable.

\section{Funding}

No funding was received.

\section{Availability of data and materials}

The datasets used and/or analyzed during the current study are available from the corresponding author on reasonable request.

\section{Authors' contributions}

YL was involved in drafting the manuscript. YL and XW performed PCR and ELISA. JW analyzed the general data of patients. All authors read and approved the final manuscript.

\section{Ethics approval and consent to participate}

This study was approved by the Ethics Committee of Traditional Chinese Medical Hospital of Huangdao District (Qingdao, China) and Weifang Medical University Hospital (Weifang, China). Signed informed consents were obtained from the patients or the guardians.

\section{Patient consent for publication}

Not applicable.

\section{Competing interests}

The authors declare that they have no competing interests. 


\section{References}

1. Li D, Xie K, Wolff R and Abbruzzese JL: Pancreatic cancer. Lancet 363: 1049-1057, 2004.

2. Vincent A, Herman J, Schulick R, Hruban RH and Goggins M: Pancreatic cancer. Lancet 378: 607-620, 2011.

3. Rochefort MM, Ankeny JS, Kadera BE, Donald GW, Isacoff W, Wainberg ZA, Hines OJ, Donahue TR, Reber HA and Tomlinson JS: Impact of tumor grade on pancreatic cancer prognosis: Validation of a novel TNMG staging system. Ann Surg Oncol 20: 4322-4329, 2013.

4. Koliopanos A, Avgerinos C, Farfaras A, Manes C and Dervenis C: Radical resection of pancreatic cancer. Hepatobiliary Pancreat Dis Int 7: 11-18, 2008.

5. Abe M, Kondo S, Hirano S, Ambo Y, Tanaka E, Morikawa T, Okushiba $\mathrm{S}$ and Katoh $\mathrm{H}$ : Long-term survival after radical resection of advanced pancreatic cancer: A case report with special reference to $\mathrm{CD} 8^{+} \mathrm{T}$-cell infiltration. Int $\mathrm{J}$ Gastrointest Cancer 33: 107-110, 2003.

6. Lowenfels AB and Maisonneuve P: Epidemiology and risk factors for pancreatic cancer. Best Pract Res Clin Gastroenterol 20 197-209, 2006.

7. Kashiwagi Y, Kato N, Sassa T, Nishitsuka K, Yamamoto T, Takamura $\mathrm{H}$ and Yamashita $\mathrm{H}$ : Cotylenin A inhibits cell proliferation and induces apoptosis and PAX6 mRNA transcripts in retinoblastoma cell lines. Mol Vis 16: 970-982, 2010.

8. Tchernitsa O, Kasajima A, Schäfer R, Kuban RJ, Ungethüm U, Györffy B, Neumann U, Simon E, Weichert W, Ebert MP, et al: Systematic evaluation of the miRNA-ome and its downstream effects on mRNA expression identifies gastric cancer progression. J Pathol 222: 310-319, 2010.

9. He B, Li T, Guan L, Liu FE, Chen XM, Zhao J, Lin S, Liu ZZ and Zhang HQ: CTNNA3 is a tumor suppressor in hepatocellular carcinomas and is inhibited by miR-425. Oncotarget 7: 8078-8089, 2016.

10. Li L, Chen HZ, Chen FF, Li F, Wang M, Wang L, Li YQ and Gao DS: Global microRNA expression profiling reveals differential expression of target genes in 6-hydroxydopamine-injured MN9D cells. Neuromolecular Med 15: 593-604, 2013.

11. Yu J, Li A, Hong SM, Hruban RH and Goggins M: MicroRNA alterations of pancreatic intraepithelial neoplasias. Clin Cancer Res 18: 981-992, 2012.

12. Ding C, Xu J and Li J: ABT-874, a fully human monoclonal antiIL-12/IL-23 antibody for the potential treatment of autoimmune diseases. Curr Opin Investig Drugs 9: 515-522, 2008.
13. Langowski JL, Zhang X, Wu L, Mattson JD, Chen T, Smith K, Basham B, McClanahan T, Kastelein RA and Oft M: IL-23 promotes tumour incidence and growth. Nature 442: 461-465, 2006.

14. Livak KJ and Schmittgen TD: Analysis of relative gene expression data using realtime quantitative PCR and the 2(-Delta Delta C(T)) method. Methods 25: 402-408, 2001.

15. Siegel R, Naishadham D and Jemal A: Cancer statistics, 2013. CA Cancer J Clin 63: 11-30, 2013.

16. Zhang Z, Wen M, Guo J, Shi J, Wang Z, Tan B, Zhang G, Zheng $X$ and Zhang A: Clinical value of miR-425-5p detection and its association with cell proliferation and apoptosis of gastric cancer. Pathol Res Pract 213: 929-937, 2017.

17. Ciric B, El-behi M, Cabrera R, Zhang GX and Rostami A: IL-23 drives pathogenic IL-17-producing CD8 ${ }^{+} \mathrm{T}$ cells. J Immunol 182: 5296-5305, 2009.

18. Shime H, Yabu M, Akazawa T, Kodama K, Matsumoto M, Seya T and Inoue N: Tumor-secreted lactic acid promotes IL-23/IL-17 proinflammatory pathway. J Immunol 180: 7175-7183, 2008.

19. Chen G, Liang Y, Guan X, Chen H, Liu Q, Lin B, Chen C, Huang M, Chen J, Wu W, et al: Circulating low IL-23: IL-35 cytokine ratio promotes progression associated with poor prognosisin breast cancer. Am J Transl Res 8: 2255-2264, 2016.

20. Khodadadi A, Razmkhah M, Eskandari AR, Hosseini A, Habibagahi M, Ghaderi A and Jaberipour M: IL-23/IL-27 ratio in peripheral blood of patients with breast cancer. Iran J Med Sci 39: 350-356, 2014.

21. Sun L, Jiang R, Li J, Wang B, Ma C, Lv Y and Mu N: MicoRNA$425-5 p$ is a potential prognostic biomarker for cervical cancer. Ann Clin Biochem 54: 127-133, 2017.

22. Petanidis S, Anestakis D, Argyraki M, Hadzopoulou-Cladaras M and Salifoglou A: Differential expression of IL-17, 22 and 23 in the progression of colorectal cancer in patients with K-ras mutation: Ras signal inhibition and crosstalk with GM-CSF and IFN- $\gamma$. PLoS One 8: e73616, 2013.

23. Qian X, Gu L, Ning H, Zhang Y, Hsueh EC, Fu M, Hu X, Wei L, Hoft DF and Liu J: Increased Th17 cells in the tumor microenvironment is mediated by IL-23 via tumor-secreted prostaglandin E2. J Immunol 190: 5894-5902, 2013.

This work is licensed under a Creative Commons Attribution-NonCommercial-NoDerivatives 4.0 International (CC BY-NC-ND 4.0) License. 